J. Lake Sci. (湖泊科学), 2014, 26(1): 113-120

http : //www. jlakes.org. E-mail : jlakes@niglas.ac.cn

(C) 2014 by Journal of Lake Sciences

\title{
三种碳源对乌梁素海好氧不产氧光合细菌群落结构的影响"
}

\author{
赵吉点 ${ }^{1}$, 巩瑞红 ${ }^{1 * *}$, 李畅游 ${ }^{2}$, 王瑞刚 ${ }^{1}$, 陈 晨 $^{1}$, 陈勿力吉玛 ${ }^{1}$, 牛晓峰 ${ }^{3}$, 冯福应 ${ }^{1 * * * *}$ \\ ( 1 : 内蒙古农业大学生命科学学院应用与环境微生物研究所, 呼和浩特 010018) \\ ( 2 : 内蒙古农业大学水利与土木建筑工程学院, 呼和浩特 010018) \\ (3: 内蒙古自治区赤峰市喀喇沈旗锦山镇人民政府,赤峰 024400)
}

摘 要: 好氧不产氧光合细菌 (AAPB) 营光合异养, 在水体碳循环中起着重要作用. 但是, 碳源对 AAPB 群落结构的影响 尚不明确. 本文基于 $16 \mathrm{~S} \mathrm{rDNA}$ 和光合反应中心合成中的关键基因— $p u f M$ 基因,运用变性梯度凝胶电泳( DGGE) 技术, 比较分析了在微生物分离培养中常用的 3 种碳源 (葡萄糖、丙酩酸钠、酵母提取物) 对乌梁素海水体总细菌及 AAPB 群落 结构的影响. 结果表明, 不同碳源诱导 $7 \sim 21 \mathrm{~d}$ 后, 水体总细菌群落丰富度及多样性指数均有不同程度的提升, AAPB 群落 则呈现先升后降的趋势. 3 种碳源中, 丙酮酸钠添加后对总细菌及 AAPB 菌群的丰富度和多样性的提升效果最好. 测序及 系统发育结果表明, 乌梁素海水体经诱导后新检测到了一些原环境中未发现的菌属, 一些具有特殊碳代谢能力的菌属丰 度得到了提升. 本研究为充分认识和理解 AAPB 的生态学作用和意义,及其富集、分离和培养提供了基础依据.

关键词: 好氧不产氧光合细菌; 碳源; 群落结构;变性梯度凝胶电泳;乌梁素海

\section{Influence of three kinds of carbon source on community structure of aerobic anoxygenic phototrophic bacteria in Lake Ulansuhai}

\author{
ZHAO Jirui ${ }^{1}$, GONG Ruihong ${ }^{1}$, LI Changyou ${ }^{2}$, WANG Ruigang ${ }^{1}$, CHEN Chen ${ }^{1}$, CHEN Wulijima ${ }^{1}$, NIU Xi- \\ aofeng $^{3}$ \& FENG Fuying ${ }^{1}$ \\ (1: Institute for Applied and Environmental Microbiology of Life Sciences College, Inner Mongolia Agricultural University, \\ Huhhot 010018 , P. R. China) \\ (2: Water Conservancy and Civil Engineering College, Inner Mongolia Agricultural University, Huhhot 010018, P. R. China) \\ (3: People's Government of Jinshan Town in Harcin County, Chifeng 024400, P. R. China)
}

\begin{abstract}
Aerobic anoxygenic phototrophic bacteria (AAPB) are photoheterotrophic microbes and play a significant role in carbon cycle in aquatic ecosystems. However, the effect of carbon source on the community structure of AAPB remains unknown presently. This study determined the influence of three carbon sources, glucose, sodium pyruvate and yeast extract common used in microbe isolation and culture on total bacteria and AAPB community structures of Lake Ulansuhai, using denaturing gradient gel electrophoresis based on the genes of $16 \mathrm{~S}$ rDNA and pufM of photosynthetic reaction center respectively. The results showed that diversity and richness of total bacteria community had been enhanced while those of AAPB community been improved previous to 14 days then decreased, after inducing by different carbon sources for $7-21$ days. Among the three carbon sources, sodium pyruvate best increased the richness and diversity of both total bacteria and AAPB. Sequencing and phylogenetic analysis revealed that some taxonomic strains were discovered which failed to be determined before induction by carbon source and moreover the abundance of some strains harboring specific carbon metabolism were greatly elevated. These results may promote the appreciation for the function and significance of $\mathrm{AAPB}$ and provide the basis for their enrichment, isolation and culture.
\end{abstract}

Keywords: Aerobic anoxygenic phototrophic bacteria; carbon source; community structure; denaturing gradient gel electrophoresis; Lake Ulansuhai

* 国家自然科学基金项目(30760004) 和内蒙古农业大学科技创新团队基金项目( NDPYTD2010-3) 联合资助. 2013 03-15 收稿;2013-04-25 收修改稿. 赵吉睿(1987 ), 男, 硕士研究生; E-mail : zhaojiruidu@ 163. com.

** 并列第一作者; 巩瑞红(1989 ), 女, 硕士研究生; E-mail: grh306@ 163. com.

*** 通信作者;E-mail: fengfuying2006@126.com. 
好氧不产氧光合细菌 (Aerobic anoxygenic phototrophic bacteria, AAPB) 是在有氧条件下以有机物、硫化 物或氨等作为供氢体, 通过细菌叶绿素捕获光能进行光合作用但并不释放氧气的一类原核生物 ${ }^{[1]}$. AAPB 广泛分布于海洋、热泉、河流、内陆湖泊等各种环境 ${ }^{[2]}$. 其生物量占整个微生物群落的比例, 在海洋中约为 $11 \%$,在河口中最高可达 $34 \%$, 而在一些高山湖泊中的比例甚至超过了 $50 \%{ }^{[3-4]}$.

AAPB 营光合异养的营养方式: 溶解有机质 (DOM) 作为有机碳的来源维持生长代谢, 同时它作为具有 光合作用功能的细菌, 以光合作用作为异养代谢的能量补充. 因此, AAPB 在水体碳循环中起着重要作用 ${ }^{[3]}$. AAPB 可利用的碳源十分丰富, 如有机酸、碳水化合物、乙醇和复杂的有机体等 ${ }^{[5]}$. 葡萄糖、丙酮酸钠和酵母 提取物常用作 AAPB 分离和培养的碳源, 且培养效果较好 ${ }^{[6]}$. 然而, 这些碳源对 AAPB 群落结构的影响究竟 如何尚不清楚. 本研究通过对内蒙古高原湖泊乌梁素海水体分别添加葡萄糖、丙酮酸钠及酵母提取物进行 室内诱导实验, 以分析 AAPB 在经 3 种碳源诱导后群落结构的变化, 为理解 AAPB 广泛的环境适应性、在碳 循环中的作用及其菌种的分离和培养提供依据.

乌梁素海 $\left(40^{\circ} 47^{\prime} \sim 41^{\circ} 03^{\prime} \mathrm{N}, 108^{\circ} 43^{\prime} \sim 108^{\circ} 57^{\prime} \mathrm{E}\right)$, 位于内蒙古西部巴盟乌拉特前旗境内, 属浅水湖泊 (平均水深约 $1.0 \mathrm{~m}$, 最深约 $2.5 \mathrm{~m}$ ), 南北长约 $35 \sim 40 \mathrm{~km}$, 东西宽约 $5 \sim 10 \mathrm{~km}$, 湖面平均高程约为 $1018.5 \mathrm{~m}$, 湖泊容量为 $2.5 \times 10^{8} \sim 3.3 \times 10^{8} \mathrm{~m}^{3}$, 湖面海拔 $1018.79 \mathrm{~m}$, 现有水域面积约 $293 \mathrm{~km}^{2}$, 湖水最终由最南端汇人 黄河, 是黄河流域最大的湖泊, 是地球上同纬度地区最大的自然湿地 (已列入世界湿地公约). 由于地处冬季 寒冷干燥、夏季炎热少雨的全球半荒漠地区, 乌梁素海成为了我国北方重要的生态屏障, 在维持地区的生态 平衡、保护物种的多样性方面起着举足轻重的作用 ${ }^{[7]}$.

\section{1 材料和方法}

\section{1 样品采集、碳源添加和培养}

于 2010 年 8 月内蒙古乌梁素海污染较严重的红圪卜湖区 (HGB) (图 1) 采集表层 $\left(0 \sim 20 \mathrm{~cm}\right.$ ) 水样 ${ }^{[8]}$. 样品置于低温 $\left(4^{\circ} \mathrm{C}\right)$ 迅速运回实验室, 分别在 $500 \mathrm{ml}$ 三角瓶中分装人 $300 \mathrm{ml}$ 水样. 之后, 分别添加葡萄糖、 丙酮酸钠、酵母提取物 3 种碳源, 至其在分装水样中总浓度分别均达到 $0.5 \mathrm{~g} / \mathrm{L}$. 每种碳源添加处理分别设置 6 个平行进行培养. 样品编号如下: 对照组 ( N0、N7、N14、N21), 加葡萄糖组 (G7、G14、G21), 丙酮酸钠组 (B7、B14、B21), 酵母提取物组 $(\mathrm{Y} 7 、 \mathrm{Y} 14 、 \mathrm{Y} 21)$, 编号中的数字代表取样时的培养天数. 培养条件为: $28^{\circ} \mathrm{C}$ 恒 温, 光暗周期为 $14 \mathrm{~h}: 10 \mathrm{~h}$.

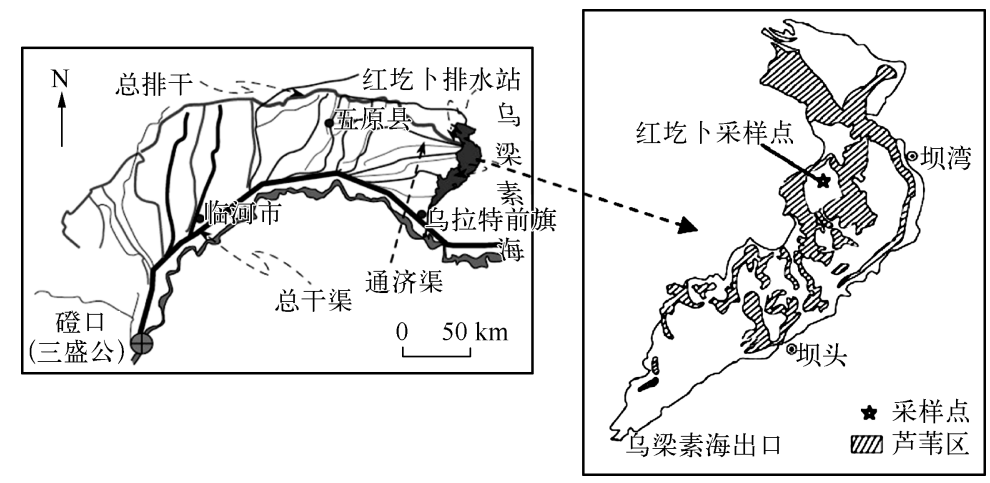

图 1 乌梁素海采样点分布

Fig. 1 Distribution of sampling site in Lake Ulansuhai

\section{2 细菌过滤收集}

分别在培养 $0 、 7 、 14$ 和 $21 \mathrm{~d}$ 后于超净台中从各平行样中取出 $50 \mathrm{ml}$ 水样, 添加同种碳源的水样混合后过 滤. 样品过滤时先用 $10 \mu \mathrm{m}$ 孔径的滤膜 (所有滤膜均为美国 Millipore 公司生产, 直径 $45 \mathrm{~mm}$ ) 过滤以去除颗 粒杂质以及真核生物, 随后用 $0.22 \mu \mathrm{m}$ 滤膜过滤, 每张膜过滤 $100 \mathrm{ml}$ 水样. 将过滤好的滤膜用铝䈃纸包好, 经液氮速冻后放人 $-70^{\circ} \mathrm{C}$ 保存备用. 而取样后将剩余培养液置于 1.1 节中所述培养条件下继续培养. 


\section{3 样品总 DNA 的提取及 PCR 扩增}

在超净台中用经灼烧灭菌的剪刀将上述冻存的滤膜剪成小碎片 (大小约 $1 \mathrm{~mm} \times 1 \mathrm{~mm}$ ), 装人 $10 \mathrm{ml}$ 离心 管之后参考 Boström 等 ${ }^{[11]}$ 的方法, 采用酶解和反复冻融结合法提取 DNA. 以提取的总 DNA 为模版, 用 F341GC ( 5'-CGCCCGCCGCGCGCGGCGGGCGGGGCGGGGGCACGGGGGGCCTAGGGAGGCAGCAG-3') 及 R907 ( 5' CCGTCAATTCMTTTGAGTTT-3') 引物扩增 16S rDNA V3 V5 区片段. 用特异性引物 UNIF ( $5^{\prime}$-GGNAAYYTNTWYTAYAAYCCNTTYCA-3' $)$ 及 GC-WAW ( $5^{\prime}$-CCGCCGCGCGGCGGGCGGGGGGGGGCACCGGGGAYNGCRAACCACCANGCCCA-3') 扩增 pufM 片段 ${ }^{[12]}$. 2 个片段的 PCR 反应体系为: $2 \mu \mathrm{l} \mathrm{DNA}$ 模板 (约 $50 \mathrm{ng} / \mu \mathrm{l}$ ), $0.4 \mu \mathrm{l}$ Easy-Taq 酶, $5 \mu \mathrm{l}$ 扩增 Buffer, $4 \mu \mathrm{l} \mathrm{dNTP}(20 \mathrm{mmol} / \mathrm{L})$, 引物 $(20 \mu \mathrm{mol} / \mathrm{L})$ 各 $0.5 \mu \mathrm{l}, \mathrm{Mg}^{2+}$ 终浓度为 $3 \mathrm{mmol} / \mathrm{L}$, 补水使总体积至 $50 \mu \mathrm{l}$.

使用梯度 PCR 仪 (Veriti9026, ABI, Germany) 进行目的基因扩增. $16 \mathrm{~S}$ rDNA 片段扩增条件为: $94^{\circ} \mathrm{C}$ 预变 性 $5 \mathrm{~min}$; 每个循环为 $94^{\circ} \mathrm{C}$ 下变性 $1 \mathrm{~min}, 55^{\circ} \mathrm{C}$ 下退火 $1 \mathrm{~min}, 72^{\circ} \mathrm{C}$ 延伸 $1 \mathrm{~min}$, 共 30 个循环; 最后, 在 $72^{\circ} \mathrm{C}$ 下延 伸 $10 \mathrm{~min}$. pufM 片段扩增条件为: $94^{\circ} \mathrm{C}$ 预变性 $3 \mathrm{~min}$; 每个循环为 $94^{\circ} \mathrm{C}$ 下变性 $30 \mathrm{~s}, 50{ }^{\circ} \mathrm{C}$ 下退火 $45 \mathrm{~s}, 72^{\circ} \mathrm{C}$ 延伸 $45 \mathrm{~s}$, 共 35 个循环; 最后, 在 $72^{\circ} \mathrm{C}$ 下延伸 $10 \mathrm{~min} .2$ 个基因的扩增产物经 $1 \%$ 的琼脂糖凝胶电泳进行检测.

\section{4 变性梯度凝胶电泳 (DGGE) 分析}

运用基因突变检测仪 (Dcode, Bio-rad, US) 对 $16 \mathrm{~S} \mathrm{rDNA}^{[10]}$ 及 pufM 基因 ${ }^{[11]}$ 进行 DGGE 分析: 聚丙烯酰胺 凝胶浓度为 $6 \%$ (用于 $16 \mathrm{~S} \mathrm{rDNA}$ 分析) 或 $8 \%$ (用于 $p u f M$ 基因分析), 电泳缓冲液为 $1 \times \mathrm{TAE}$, 变性梯度为 $45 \% \sim 60 \%$; PCR 产物上样量为 $300 \mathrm{ng}$ DNA; 电压 $80 \mathrm{~V}, 60^{\circ} \mathrm{C}$, 电泳 $13 \mathrm{~h}$; 用 $0.2 \%$ 硝酸银溶液染色 $15 \mathrm{~min}$, 后 用 Gel DocTM EQ imager (Bio-Rad) 成像拍照.

\subsection{DGGE 条带的序列测定及系统发育树的构建}

用无菌刀片切割 DGGE 凝胶中的 DNA 条带, 将切下后的不同条带分别放人 $1.5 \mathrm{ml} \mathrm{EP}$ 管中, 以无菌去 离子水冲洗 5 遍后, 在 $\mathrm{EP}$ 管中加人 $40 \mu \mathrm{l}$ 无菌水、置于 $4{ }^{\circ} \mathrm{C}$ 过夜, 以使胶中的 DNA 溶出. 之后, 轻微振荡混匀 再在 1000 转/ $\min$ 低速离心, 吸取 $1 \mu \mathrm{l}$ 上清液作为模板, 用不含 $\mathrm{GC}$ 夹的引物, 以与 1.2 节中相同的扩增程序 及体系进行扩增. 将纯化后的 PCR 产物与 pEASY-T1 载体连接, 并转化人大肠杆菌 DH5 $\alpha$ 感受态细胞, 将阳 性克隆送北京华大生物技术有限公司用 ABI 3730XL 型测序仪进行测序. 手动去除载体序列, 将有效序列在 NCBI 上进行比对, 以其中同源性最高的序列确定为参比菌株, 并用 Mega 5.1 软件, 基于 Kimura-2 参数模型 计算进化距离; 用邻接法 (Neighbor Joining Method) 构建系统进化树 ${ }^{[13]}$, 重复验证数为 1000 .

\section{6 细菌群落多样性的统计学分析}

应用 Quantity One 4.4.0 (Bio-Rad) 对 DGGE 电泳图谱进行聚类分析, 比较不同样品中菌群的基因型差 异; 香农一威纳多样性指数 (Shannon-Wiener 指数, $H^{\prime}$ )、丰富度 $(R)$ 和均匀度指数 $\left(E_{\mathrm{H}}\right)$ 被用来比较各个样品 的细菌多样性 ${ }^{[14]}$, 计算公式分别为:

$$
\begin{gathered}
H^{\prime}=-\sum_{i=1}^{S} P_{i} \ln P_{i} \\
R=S \\
E_{\mathrm{H}}=H^{\prime} / H_{\text {max }}=H^{\prime} / \ln S
\end{gathered}
$$

式中, $P_{i}$ 是某个样品中 $i$ 条带的强度占所有条带总强度的比率, $S$ 是某个样品中所有条带数目总和.

\section{2 结果}

\subsection{DGGE 图谱和群落多样性指数分析}

$16 \mathrm{~S}$ rDNA 的 DGGE 图谱分析表明, 所有样品可分离到 $15 \sim 25$ 条条带 (图 2a). 葡萄糖诱导 $21 \mathrm{~d}$ 的样品 条带数最少, 为 15 条; 丙酮酸钠诱导 $7 \mathrm{~d}$ 的样品条带数最多, 为 25 条, 各样品条带丰富度差异较大 (表 1 ). 碳源诱导后乌梁素海水样菌群多样性变化趋势与丰富度的变化趋势类似, 其中 $7 \sim 14 \mathrm{~d}$ 诱导过程中, 丙酮酸 钠诱导后水体总细菌 Shannon-Wiener 指数从 3.037 升至 3.324, 提高了约 10\%, 在 3 种碳源中提高幅度最 大; 其次为葡萄糖, 从 3.160 升至 3.359 , 提高约 $8 \%$. 不同时期对照样品的均匀度指数 $\left(E_{\mathrm{H}}\right)$ 均较高, 在添加 
碳源后各样品均匀度指数相比对照均略有下降, 但在 $21 \mathrm{~d}$ 时恢复至 $0.91 \sim 0.96$ (表 1 ).

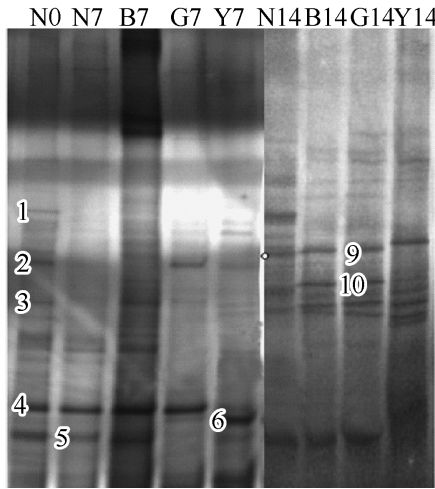

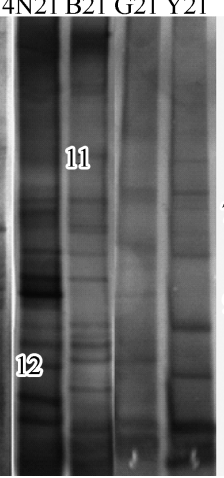

b

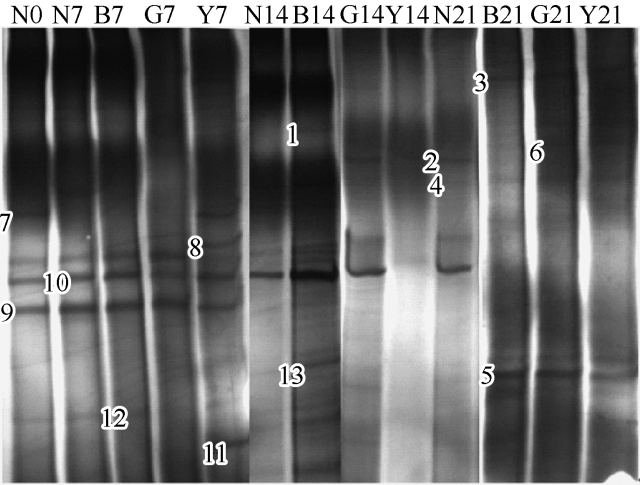

图 2 水体样品中细菌 $16 \mathrm{~S}$ rDNA 基因 (a) 和 $p u f M$ 基因 (b) DGGE 图谱(图谱上端字母和数字为样品编号: $\mathrm{N}$ 代表未添加任何碳源 $; \mathrm{B} 、 \mathrm{G}$ 和 $\mathrm{Y}$ 分别代表添加丙酮酸钠、葡萄糖和酵母提取物 ; 数字代表相应取样时的培养天数;条带 $1 \sim 12$ 为切胶回收条带)

Fig. 2 DGGE profile of bacterial $16 \mathrm{~S} \operatorname{rDNA}(\mathrm{a})$ and $\operatorname{pufM(b)}$ in water samples(The symbols on the top: $\mathrm{N}$ represents nothing added; $\mathrm{B}, \mathrm{G}$ and $\mathrm{Y}$ indicate the addition of sodium pyruvate, glucose and yeast extracts, respectively; the numbers show the culture days when sampling; Bands 1-12 indicate the excised bands)

表 1 细菌 $16 \mathrm{~S}$ rDNA 基因和 $p u f M$ 基因丰富度、 多样性指数及均匀度指数分析

Tab. 1 Diversity analysis of samples estimated by 16S rDNA-DGGE and pufM-DGGE bands patterns

\begin{tabular}{ccccccccc}
\hline \multirow{2}{*}{ 样品 } & \multicolumn{3}{c}{$16 \mathrm{~S}$ rDNA } & & \multicolumn{3}{c}{$p u f M$} \\
\cline { 2 - 5 } \cline { 7 - 8 } & $R$ & $H^{\prime}$ & $E_{\mathrm{H}}$ & & $R$ & $H^{\prime}$ & $E_{\mathrm{H}}$ \\
\hline N0 & 21 & 3.063 & 0.991 & & 8 & 2.183 & 0.893 \\
N7 & 19 & 3.030 & 0.995 & & 8 & 2.054 & 0.879 \\
B7 & 25 & 3.037 & 0.997 & & 7 & 1.843 & 0.883 \\
G7 & 22 & 3.160 & 0.998 & & 6 & 1.878 & 0.865 \\
Y7 & 21 & 3.087 & 0.997 & & 10 & 2.172 & 0.875 \\
N14 & 18 & 3.322 & 0.997 & & 9 & 2.116 & 0.866 \\
B14 & 18 & 3.324 & 0.998 & & 15 & 2.615 & 0.903 \\
G14 & 16 & 3.359 & 0.998 & & 9 & 2.287 & 0.880 \\
Y14 & 19 & 3.459 & 0.998 & & 5 & 1.875 & 0.863 \\
N21 & 19 & 3.482 & 0.996 & & 7 & 2.116 & 0.864 \\
B21 & 20 & 3.118 & 0.998 & & 8 & 2.015 & 0.887 \\
G21 & 15 & 3.016 & 0.997 & & 6 & 2.087 & 0.875 \\
Y21 & 18 & 3.148 & 0.998 & & 8 & 1.987 & 0.856 \\
\hline
\end{tabular}

$p u f M$ 基因的 DGGE 图谱(图 2b) 表明,各样 品条带数从 5 到 15 条不等, 丰富度变化较大. 其中丙酮酸钠诱导 $14 \mathrm{~d}$ 后样品条带数最多, 与 $16 \mathrm{~S}$ rDNA-DGGE 的分析结果相似. 各样品细菌 多样性指数及均匀度指数均发生不同程度的变 化(表 1). 对照样品的好氧不产氧光合细菌 (aerobic anoxygenic phototrophic bacteria, AAPB) 群落的 Shannon-Wiener 指数在 $0 \sim 21 \mathrm{~d}$ 培养过 程中变化不大, 而添加丙酮酸钠及葡萄糖诱导样 品在培养 $7 \sim 21 \mathrm{~d}$ 过程中均呈现先升后降的趋 势, 但酵母提取物诱导样品则表现出先降后升 的趋势. AAPB 群落丰富度指数与 Shannon-Wiener 指数变化规律一致. 各样品的均匀度指数差 别均不大, 丙酮酸钠诱导 $14 \mathrm{~d}$ 的样品群落均匀 度指数达 0.903 , 为各样品中的最高值.

\section{2 条带测序及系统发育分析}

分别选取 $16 \mathrm{~S}$ rDNA 和 pufM 的 PCR-DGGE 指纹图谱中差异条带进行切胶回收、测序,最后 共得到 12 条 $16 \mathrm{~S}$ rDNA 和 13 条 pufM 序列. 系统

发育分析结果(图 3A) 表明,16S-band 1 出现在 N、Y7、G7、N14、N21、B21、Y21 等样品中, 与 Paracoccus mari$n u s$ 相近, 该菌是一类分离自海洋环境, 具有产糖能力的好氧细菌 ${ }^{[15]}$. 在诱导过程中, 该条带在 G7、Y7 时变 弱, 而后在 G14、Y14 时消失, 但至 $21 \mathrm{~d}$ 时, 该条带又再度出现, 且亮度较原始对照样品有所提升. 16S-band 4 从原始样品至 $7 \mathrm{~d}$ 诱导过程中始终存在, 与耐盐菌 Halobacillus trueperi 相近, 推测与乌梁素海水体的轻微盐 碱性有关. 16S-band 6 序列与从石油污染海区分离到的 Thalassospira xianhensis 相似, 据报道该菌属有着降解 多环芳烃的能力 ${ }^{[6]} .16 \mathrm{~S}-$ band $9 、 10$ 是在诱导至 $14 \mathrm{~d}$ 时亮度提升的条带, 并在各种碳源诱导的样品中均有所 
出现, 经比对发现 16S-band 9 与 Geobacillus stearothermophilus 有着 $99 \%$ 的同源性, 该菌有着降解污染物, 利用 糖类的能力,推测该条带的变化与相关碳源处理有着密切关系. 16S-band 11 在 N、N7、B14、G14、Y14、B21、 $\mathrm{Y} 21$ 这 7 个样品中均有出现, 条带亮度在处理过程中其丰富度随诱导时间的延长略有提升. 比对后发现该 条带与 Pseudoalteromonas sp. 有 $99 \%$ 的相似性, 该菌分离自海洋环境, 具有产胞内抗菌素的能力. 16S-band 5 除 G7 和 Y14 外的其他样品中均存在, 与 Uncultured Flavobacteriales bacterium 的相似性为 99\%, 该菌为常见 的水生类群. 其余的 4 条带 (16S-band 2、3、9、12) 与不可培养菌序列相似, 比对发现均来自湖泊湾口等水体 环境. 系统发育树 (图 3A) 显示 $16 \mathrm{~S}$ rDNA 序列在系统发育树上全部属于蛋白菌门( Proteobacteria). 分属于其 下所包含的 4 个亚类群, 分别是 Alphaproteobacteria、Betaproteobacteria、Gammaproteobacteria、Deltaproteobacteria. 可知 Proteobacteria 始终为乌梁素海水体中的优势类群.

pufM 基因系统发育分析结果(图 3B 和 C) 表明,13 条 pufM 序列分属于 Alphaproteobacteria 及 Gammaproteobacteria 两大类群. 条带 puf-band 1 在 Y7、G14、G21、Y21 均有出现, 与 Porphyrobacter tepidarius 有 $93 \%$ 的相 似性, 据报道该菌属从热泉及海洋中均曾分离得到, 具有耐热性, 能够以葡萄糖和酵母提取物作为能量来 源 $^{[16]}$. puf-band 2 在 G7、G14、N21 中均有所发现, 其序列与自波罗的海分离得到, 具有较强产叶绿素能力的 Erythromicrobium sp. 的相似性为 $91 \%{ }^{[9]}$. puf-band 8 从原始样品至 $7 \mathrm{~d}$ 诱导过程中始终存在且条带亮度基本 不变, 至 $14 \mathrm{~d}$ 诱导时仅在对照及丙酮酸钠诱导样品中出现, 之后至 $21 \mathrm{~d}$ 时则完全消失; puf-band 10 作为原始 至 $7 \mathrm{~d}$ 诱导样品的优势条带, 至 $14 \mathrm{~d}$ 时仅 Y14 样品条带亮度较弱, 其余变化不大, 至 $21 \mathrm{~d}$ 时则仅在对照样品 中发现; puf-band 8、10 序列均归属于 Rhodobacter, 分别与 Rhodobacter megalophilus (96\% ) 和 Rhodobacter azotoformans $(83 \%)$ 相似. puf-band 12 仅在 N、N7、B14 中出现,与 Allochromatium sp. 相近( $92 \%)$. puf-band $4 、 7$ 均 与海洋中的不可培养种最相似,puf-band 5 与 Uncultured WHP231 bacterium clone 序列最相似.

相比其他淡水湖的研究 ${ }^{[17]}$, 本研究中发现乌梁素海水体 AAPB 中 Alphaproteobacteria 所占比例较高, 特 别是在丙酮酸钠及葡萄糖诱导处理后, 出现的 puf-band $1 、 2 、 8 、 10$ 等条带均归类于 Alphaproteobacteria. 而在 丙酮酸钠诱导处理 $14 \mathrm{~d}$ 后出现的 puf-band 12 , 则归类于淡水中罕见的 Gammaproteobacteria. 值得注意的是, $p u f$-band 3、4、6、9 在进化树上不能与其它序列聚在一起 (图 3C), 且均与海洋中不可培养菌的序列相近, 推 测可能是乌梁素海水体中特有的 AAPB 菌种.

\section{3 讨论}

\section{1 碳源诱导后细菌群落结构变化}

Baines 等 ${ }^{[18]}$ 曾提出水体环境中的可溶碳在与环境中的微生物作用后将会对水生生态系统及菌群结构 造成影响. 本研究发现, 在提升可溶碳浓度后细菌多样性和丰富度能够有所提升, 这与 Tranvik ${ }^{[19]}$ 对不同可 溶碳浓度的淡水湖泊内细菌丰富度的比较研究相一致. 葡萄糖诱导后水体菌群丰富度提升幅度很小, 可能 是由于相对 3 碳分子化合物丙酮酸钠而言, 等重量 6 碳分子化合物葡萄糖的碳含量更高, 可能并不能对整个 细菌群落丰富度起到预期的提升效果. Imazaki 等 ${ }^{[20]}$ 曾提出, 运用以丙酮酸钠为主碳源的培养基能够提高淡 水湖中细菌的可培养效率, 这与本研究结果相一致. $16 \mathrm{~S}$ rDNA 系统进化分析表明, 在碳源诱导后出现了 Thalassospira xianhensis、Geobacillus stearothermophilus、Pseudoalteromonas sp. 等类群, 其中 Pseudoalteromonas sp. 仅在丙酮酸钠诱导样品中出现, 而归属于 Alphaproteobacteria 类群包括 Thalassospira xianhensis 和 Paracoccus marinus 等菌属则仅在酵母提取物诱导样品中出现, 推测酵母提取物能够提升乌梁素海水体中的 Alphaproteobacteria 类群的丰富度.

\section{2 碳源诱导对 AAPB 群落的影响}

基于 pufM-DGGE 图谱分析后发现, 丙酮酸钠和葡萄糖 2 种碳源诱导后 AAPB 菌群的丰富度及多样性指 数均呈现了先升后降的趋势. 丙酮酸钠诱导后 AAPB 群落变化与细菌群落相似, 丰富度提升了近 1 倍, 多样 性指数也提高了约 $15 \%$. 葡萄糖添加诱导后丰富度提升 $50 \%$, 多样性指数提升约 $8 \%$. 酵母提取物添加后样 品的群落多样性变化趋势则有所不同, 丰富度下降约 $40 \%$, 体现了与另外 2 种碳源诱导后样品相反的变化 趋势. 究其原因, 可能是其中复杂的组分所致. 相比丙酮酸钠及葡萄糖这 2 种碳源, 酵母提取物含有氨基酸、 肽、核苷酸、维生素等物质, 其所包含营养成分更为复杂. 然而好氧不产氧光合细菌通常难以适应高营养的 

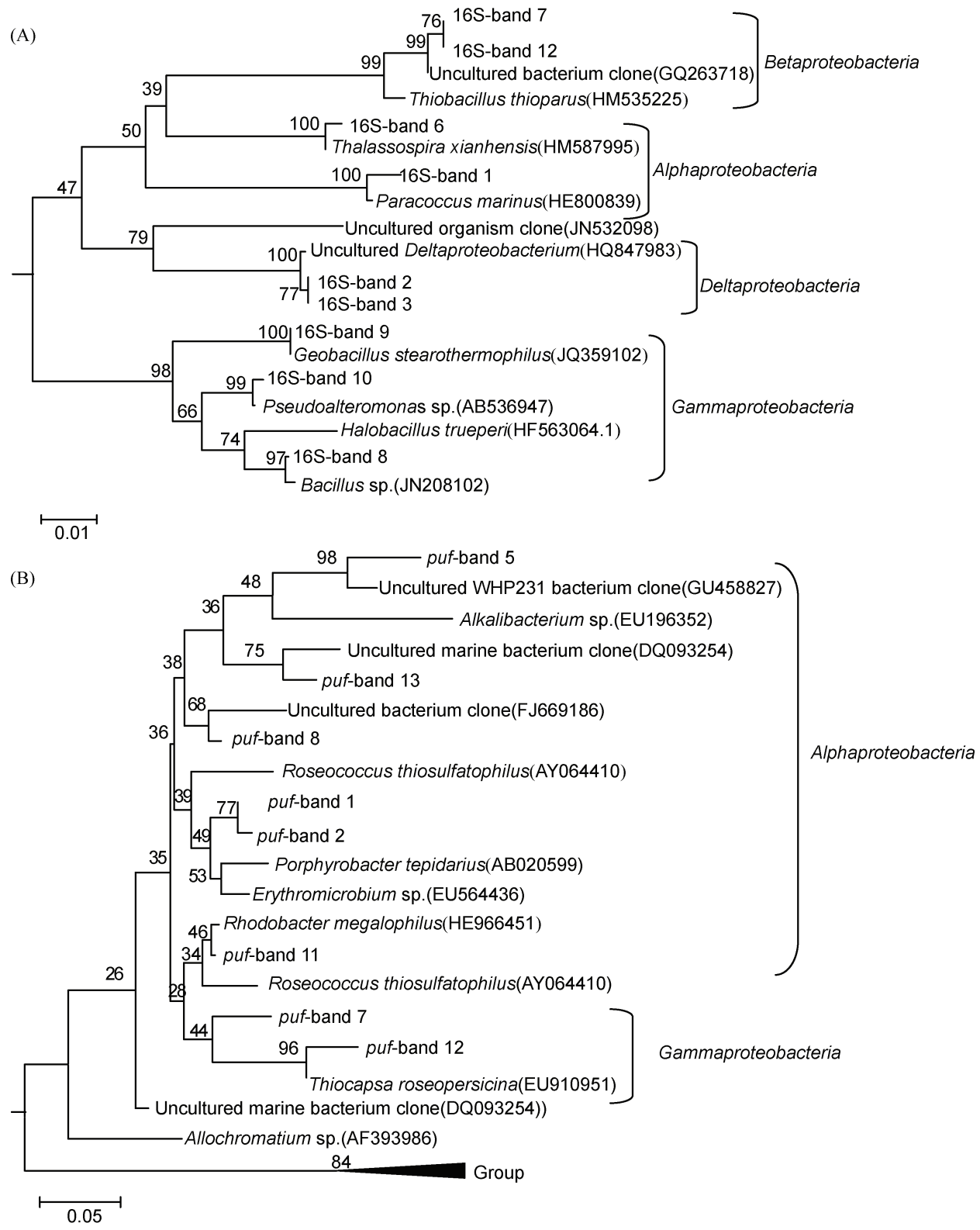

(C)

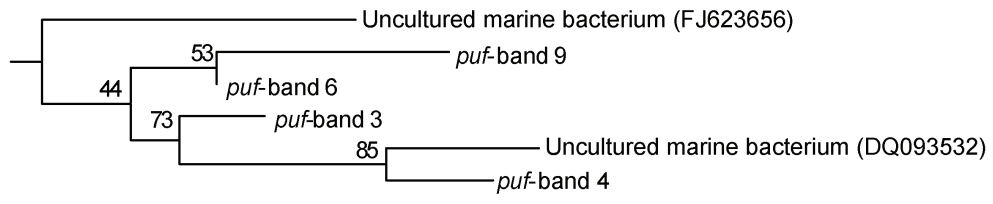

$\stackrel{\longmapsto}{ }$

图 $316 \mathrm{~S} r \mathrm{rDA}$ 基因 (A) 和 $p u f M$ 基因 (B) 序列系统发育树, $p u f M$ 基因簇 $\operatorname{Group}(\mathrm{C})$

Fig. 3 Phylogenetic tree based on 16S rDNA gene(A) and puf $M$ sequences(B) from DGGE bands, and the special group of $p u f M$ sequences( $\mathrm{C}$ ) 
培养条件, 它们更偏好于在低营养条件下进行有效的复制 ${ }^{[5]}$, 例如最早分离的 SAR11 等类群. 因此酵母提取 物可能对于偏好寡营养环境的 AAPB 而言促生作用并不显著. $21 \mathrm{~d}$ 时各样品的丰富度差别很小, 可能水体 菌群结构已经初步达到了稳态. pufM 基因的系统进化树 (图 3B) 显示, 得到的优势条带序列分属 Alphaproteobacteria 及 Gammaproteobacteria. 据报道 Alphaproteobacteria 及 Gammaproteobacteria 在海区水体中所占比例 较高, 淡水环境中很少能检测到 ${ }^{[21-22]}$; 但本研究中, 在碳源诱导后出现了 Porphyrobacter tepidarius 和 Rhodobacter megalophilus 等菌属, 使 Alphaproteobacteria 的比例非常高 (约 65\%); 此外,有 2 条序列 (puf-band 7、12)与 Thiocapsa roseopersicina 相近, 其中 puf-band 12 仅在丙酮酸钠诱导样品中检测到, 并且成为了优势类 群, 因此使得 Gammaproteobacteria 的比例达到 30\%. 比较 3 种碳源诱导样品, 发现 Porphyrobacter tepidarius, Uncultured WHP231 bacterium clone 等为丙酮酸钠诱导样品中独有的类群; Rhodobacter megalophilus 和从西藏 盐湖中所得的 Uncultured bacterium clone( FJ669186) 仅在酵母提取物诱导后样品中发现; 来自海洋的 Uncultured marine bacterium( FJ623656) 则仅在葡萄糖诱导后样品中发现. 究其原因, 一方面可能是由于乌梁素海 地处河套土壤盐碱化严重的地区, 并且该湖水循环少、蒸发量大, 使得湖水盐碱性增加, 从而出现了部分仅 在高盐环境中发现的类群; 另一方面, 则推测是碳源诱导后水体可溶碳与 AAPB 发生了互作, 水环境中的可 溶碳能够作为光能源外的营养来源去满足其生存需求, 因此当可溶性碳的电子供体进行呼吸作用时, 部分 类群 AAPB 的活性可能会有所变化 ${ }^{[5]}$, 致使参与碳循环的 AAPB 各类群比重发生了变化. 与之前针对乌梁素 海水体 AAPB 的研究相比 ${ }^{[2]}$, 本实验并未发现此前比例较高的 Betaproteobacteria. 一方面可能是由于 DGGE 技术仍具有一定局限性, 不能完全检测到环境中的细菌类群; 另一方面, 推测是水体环境中可溶碳浓度的突 然升高使得 Betaproteobacteria 难以耐受, 从而导致丰富度下降.

总之, 3 种碳源能够使得淡水环境中细菌群落结构发生较大变化, 特别是能使一些 AAPB 的功能类群丰 度增加, 表明碳源种类及环境中碳素水平与 AAPB 直接相关, 而丙酮酸钠作为本研究证实的具有良好诱导 效果的碳源,其与 AAPB 互作机理等尚待进一步研究.

\section{4 参考文献}

[ 1 ] Waidner LA, Kirchman DL. Aerobic anoxygenic phototrophic bacteria attached to particles in turbid maters of the Delaware and Chesapeake estuaries. Appl Environ Microbiol, 2007, 73(12) : 3936-3944.

[ 2 ] 何一平, 曾永辉, 袁 博等. 基于 $p u f M$ 基因的乌梁素海富营养化湖区好氧不产氧光合细菌系统发育多样性分析. 微生物学通报, 2010, 37(8): 1138-1145.

[ 3 ] Yurkov VV, Cstonyi JT. New light on aerobic anoxygenic phototrophs. In: Hunter N ed. The purple phototrophic bacteria. New York: Springer, 2009, 28: 31-55.

[ 4 ] Shi LM, Cai YF, Chen ZT et al. Diversity and abundance of aerobic anoxygenic phototrophic bacteria in two cyanobacterial bloom-forming lakes in China. Int J Lim, 2010, 46: 233-239.

[ 5 ] 张 瑶. 海洋典型功能细菌群的生态过程研究 [学位论文].厦门:厦门大学, 2006 .

[ 6 ] Zhao BS, Wang H, Li RR et al. Thalassospira xianhensis sp. nov., a polycyclic aromatic hydrocarbon-degrading marine bacterium. Int J Syst Evol Microbiol, 2010, 60(5) : 1125-1129.

[ 7 ] 李畅游, 刘廷胥, 高瑞忠等. 乌梁素海富营养化主控因子年季节变化分析及综合评价. 水文,2004, 24(3):14-17.

[ 8 ] 孙崟金鍂, 刘惠荣, 冯福应等. 乌梁素海富营养化湖区浮游细菌多样性及系统发育分析. 生物多样性, 2009, 17 (5): 490-498.

[ 9 ] Yurkov VV, Stackbrandet E, Holmes A et al. Phylogenetic positions of novel aerobic, bacteriochlorophyll $a$-containing bacteria and description of Roseococcus thiosulfatophilus gen. nov., sp. nov., Erythromicrobium ramosum gen. nov., sp. nov., and Erythrobacter litoralis sp. nov. Int J Syst Evol Microbiol, 1994, 44(3) : 427-434.

[10] Zeng YH, Feng FY, Liu YP et al. Genome sequences and photosynthesis gene cluster composition of a freshwater aerobic anoxygenic phototroph, Sandarakinorhabdus sp. strain AAP62, isolated from the Shahu Lake in Ningxia, China. Genome Announc, 2013, 1(1): e00034-13.

[11 ] Boström KH, Simu K, Hagström A et al. Optimization of DNA extraction for quantitative marine bacterioplankton community analysis. Limnol \& Oceanogr: Methods, 1998, 2: 365-373.

[12] Yutin N, Béjà O, Suzuki MT et al. The use of denaturing gradient gel electrophoresis with fully degenerate puf $M$ primers 
to monitor aerobic anoxygenic phototrophic assemblages. Limnol \& Oceanogr, 2008, 6: 427-440.

[13] Tamura K, Dudley J, Nei M et al. MEGA5: Molecular evolutionary genetics analysis using maximum likelihood, evolutionary distance, and maximum parsimony methods. Molecular Biology and Evolution, 2011, 28(10) : $2731-2739$.

[14] 刘慧杰,杨彩云, 田 蕴等. 基于 PCR-DGGE 技术的红树区微生物群落结构. 微生物学报,2010,50(7):923-930.

[15] Khan ST, Takaichi S, Harayama S. Paracoccus marinus sp. nov. , an adonixanthin diglucoside-producing bacterium isolated from coastal seawater in Tokyo Bay. Int J Syst Evol Microbiol, 2008, 58(2) : 383-386.

[16] Salka I, ̌̌uperová Z, Mašín M et al. Rhodoferax-related pufM gene cluster dominates the aerobic anoxygenic phototrophic communities in German freshwater lakes. Environ Microbiol, 2011, 13(11) : 2865-2875.

[17] 张晓晶, 李畅游, 贾克力等. 乌梁素海水体透明度分布及影响因子相关分析. 湖泊科学, 2009,21(6):879-884.

[18] Baines BS, Pace LB. The production of dissolved organic matter by phytoplankton and its importance to bacteria: patterns across marine and freshwater systems. Limnol \& Oceanogr, 1991, 36(6) : 1078-1090.

[19] Tranvik JL. Availability of dissolved organic carbon for planktonic bacteria in oligotrophic lakes of differing humic content. Limnol \& Oceanogr, 1988, 16: 311-322.

[20] Imazaki I, Kobori Y. Improving the culturability of freshwater bacteria using FW70, a low-nutrient solid medium amended with sodium pyruvate. Can J Microbio, 2010, 56: 333-341.

[21] Hanada S, Kawase Y, Hiraishi A et al. Abundance, depth distribution, and composition of aerobic bacterio chlorophyll aproducing bacteria in four basins of the central Baltic Sea. Appl Environ Microbiol, 2008, 74(14) : 4398-4404.

[22] Jiang HC, Dong HL, Yu BS et al. Abundance and diversity of aerobic anoxygenic phototrophic bacteria in saline lakes on the Tibetan plateau. FEMS Microbiol Ecol, 2009, 67(2) : 268-278. 